\title{
An integrative model of grammar teaching:From academic to communicative needs
}

\author{
Yahya Dkhissi \\ ChouaibDoukkaliUniversity, El Jadida, Morocco
}

Email address:

yahya.dkhissi@gmail.com

To cite this article:

Yahya Dkhissi. An Integrative Model of Grammar Teaching: From Academic to Communicative Needs. International Journal of Language and Linguistics. Vol. 2, No. 3, 2014, pp. 145-153. doi: 10.11648/j.ij11.20140203.13

\begin{abstract}
Language teaching has often raised the issue of students' overall academic performance. This paper deals with a foregrounding subject in language teaching namely grammar teaching. With regard to the critical situation of grammar teaching in our English departments in Morocco, this paper is based on the assumption that formal grammar teaching does not provide the expected output that the teaching-learning enterprise requires from both teachers and learners. Therefore, the objective of this paper is to review the grammar teaching methods and find out the practical solutions for the following problems: lack of coordination and consistency of methods, lack of communicative grammar text books, the difficulties in students' mastery of the English grammar even when students get plenty comprehensible input, and finally the teaching of grammar according to syllabus not students' needs. The paper concludes with a new model that engages students in a more practical, comprehensible and useful method of grammar teaching: the Exploration, production and Integration Model.
\end{abstract}

Keywords: Grammar Teaching, Needs Analysis, Exploration, Integrative Model

\section{Introduction}

Grammar teaching has often been regarded as a structure based formal activity. After the integration of several sources and techniques, which are mainly based on communicative activities, the teaching of grammar gained a new insight. In the teaching of grammar, focus on form is often modified to a meaningful structured discourse. In order to make a grammar lesson effective, beneficial, and interesting a teacher should use some well-developed, interactive and fascinating techniques in the classroom. In the present paper, the examples of such integrated sources and techniques -the use of the inductive approach along with communication and problem solving activities- are assumed to be mostly motivating for a successful grammar teaching method. The approach advocates a more integrative model of grammar teaching based on three basic steps: Exploration, Production and Integration.

\subsection{Historical Background}

Not many Moroccan English teachers relish the thought of teaching grammar due to the complexity and irregularities in the syntax of the English language. Teachers often ask what exactly the best method to teach grammar is. In the early days of grammar teaching, the (methodological) grammar translation method required students to do the toughest tasks of translating sentences into English based on grammar rules. Thus, students may end up constructing sentences that are grammatically correct but would be perceived as not interpretable or 'unacceptable' by most native speakers (Howatt, 1984).

In the 1940s and 50s the audio-lingual method was popularized by behavioural psychologists such as Skinner and Watson. Teaching grammar was simply making students learn language habits through various drills and pattern practices (Brown, 1994). However, there were problems with this method as there was no focus on "the intentions, thinking, conscious planning and internal processes of the learner" (Stern, 1984, p.305).

In the 1970s and 80s the Communicative Approach propelled by sociolinguists was replaced the audio-lingual method. This approach focuses on meaning rather than form (grammar rules) as it was believed that it is meaning which drives language acquisition and development. Ellis (1994) noted in his review of research in the 1970s that much of the Communicative L2 teaching focused on meaning only. The question teachers now often ask is whether a return to grammar teaching is necessary. If so, 
should grammar be taught implicitly or explicitly?

Any decision that should be taken about the method to be used for any curriculum be it grammar, writing, literature, culture or linguistics is supposed to take into consideration the classroom environment, teaching resources and methods of evaluation. This means that for the sorts of analysis needed to deal with questions of the place of method in language-in-education policy a more finely grained typology is needed for at least part of the scope of Kaplan and Baldauf's model as illustrated in the following policies:

- Methods policy: policy statements dealing with questions of language teaching method;

- Materials policy: policy statements dealing with questions of textbooks and other resources for language learning;

- Curriculum policy: policy statements dealing with the goals and content of language Learning.

- Assessment policy: policy statements dealing with what is to be assessed and how.

The question that we need to start with in this framework of Needs Analysis is as follows: Which grammar method, which curriculum and for which students?

\subsubsection{Current Grammar Teaching Methods}

The grammar teaching methods to be adopted in classes are usually debatable. Some practitioners believe that grammar is the focal academic subject of languages and learners should be presented with explicit grammar courses. Others, however, think that knowing the grammar doesn't necessarily lead to language mastery. They assume that focusing on explicit grammar teaching produces unsuccessful language users.

\subsubsection{Implicit Grammar Teaching}

With regard to the pitfalls in the ongoing process of grammar teaching, some practitioners think that people can acquire language without any overt grammar instruction in the same way children learn their mother tongue. Conscious use of language forms are expected accordingly to end up with high affective filter and consequently poor language proficiency and fluency. These teachers prefer language use to language usage and focus on meaning rather than form. For language activities, they advance the use of contextualized and authentic language and do not refer to rule based teaching.

\subsubsection{Explicit Grammar Teaching}

The traditional view of language teaching which focuses on language forms presentation explains the grammar rules and practice through drilling, though the required effects are not obtained. Disaffected students who can produce correct forms on exercises and tests do consistently make errors when they try to use the language in context. In other words, students subject to this kind of teaching know a lot about the language. However, these students are unable to use the language itself appropriately in contextualized situations for different reasons. In this respect, language learning, according to the different works in the field related to materials development for language learning, recommends that course books should provide learners with more opportunities to acquire language features from frequent encounters with them during motivated exposure to language in use (Cunico, 2005; Islam, 2001; Maley, 2003). Different authors support this position from a variety of angles: Experiential learning theory claims that learners gain most from apprehending from experience before comprehending from analysis (Kolb, 1984). Comprehensible input theory states that acquisition is facilitated by meaningful and motivated exposure to language in use (Krashen, 1989, 2004). Deep processing theory also claims that meaningful encounters are necessary to achieve the deep processing needed for durable learning (Craik\& Lockhart, 1972).. There is also support for this position from Asian applied linguists (e.g. Masuhara, 2000, 2003; Mukundan, 2005a, 2005b; Renandya, 2005) who argue for a reduction in the number of textbook activities involving explicit teaching of language and an increase in opportunities for implicit learning. Yet, for reasons of the present paper, I think that the most effective way of acquiring language implicitly from motivated exposure is through opportunities to reflect on language as a structural input in different academic tasks like writing, reading or article reviews.

\subsection{The Proposal: Exploration and Integration Insteadof Explanation}

Any focus on grammar explanation and the absence of any reference to meaning can be detrimental to language teaching and learning. Grammatical competence can be helpful in producing accurate forms of language and acts in monitoring its use. However, one can communicate more or less a message with vocabulary items alone while it is impossible to do so using grammar alone. This shows that grammar alone doesn't make the language. In addition, language use can be tremendously affected by conscious language usage as this may create a stressful environment. So a learner based approach that opts for contextualization of grammar teaching takes into consideration the appropriate use of language without the internalization of the rules. A grammar-discovery approach involves then providing learners with data to illustrate a particular grammatical point and getting them to analyze it in order to reach an awareness of how the feature works. Following this line of thinking, students will be able to develop analytical skills to understand and internalize and discover language rules. Therefore, grammar becomes content for exploration and communication.

In general, research indicates that a combination of form and meaning may be the best teaching approach. A research by Prabhu (cited by Beretta \& Davis, 1985) showed that students who received meaning-based instruction did well on the meaning-based test but poorly on a discrete-point grammar test. Spada \& Lightbown (1993) postulated that "form focused instruction and corrective feedback within 
the context of communicative interaction can contribute positively to second language development in both the short and long term" (p.205). This is supported by CelceMurcia, Dornyei and Thurrell (1997) who suggest that the integration of form and meaning is gaining importance in what they refer to as the 'principled communicative approach.' Musumeci (1997) went on further to say that students should learn grammar explicitly but should also be given the opportunity to practice them in communicative authentic and simulated tasks.

\section{Grammar Teaching}

\subsection{The Rationale}

While it is essential for learners to be able to manipulate grammatical form, they also need to understand the concept(s) expressed and the function(s) performed through a particular grammatical item. For Moroccan university students for which English is a foreign language, knowledge of the rules is much needed. In this paper, I stress the urgent need for some more successful methods and drills that promote the grammar class from abstractness to a more integrative subject. This paper will discuss a blended approach to teaching and reinforcing grammar. For each item of grammar 2 (a grammar based on teaching tenses and modal verbsand grammar 3 (a grammar based on teaching sentences, phrases and clauses), specific teaching points will be highlighted. Classroom experience and management such as immediate feedback and correction will also be discussed; as for motivation, it is mostly required since it depends largely on the teacher, the method, the language activities, and the classroom situation. This puts heavy burden on the class teacher who is required to compensate and be creative in his teaching method in order to build enough motivation for learning, and develop in every possible way the four skills of language: listening, reading, speaking and writing.

\subsection{Background}

Given the confusing situation of the teaching methods applied by grammar teachers at the Moroccan university, I believe that reaching a somewhat successful teaching of grammar requires a specific care of the following factors:

\subsubsection{Students' Needs and Teachers' Goals}

The new pre-course needs analysis is important to know about his students' needs and set his goals.

\subsubsection{Class Activities and Drills}

Class activities will affect teachers' pedagogical values in the sense that they will foster more practice in classes, and more expose of students to real world.

\subsubsection{Learning Materials}

The more learning resources are available, the easier it will be to employ different strategies when teaching a given grammatical item. For example, a group of students who like using hand-outs could use the hand-outs to study a certain grammar task while another group who prefers spoken oral practice might prefer an explanation of any item with a number of examples. Others however would require practice, though practising a grammatical structure under controlled conditions does not seem to enable the learner to use the structure freely.

\subsubsection{Evaluation}

The new method of testing, the formative assessment as well as a variety of types of assessment will enable the teacher to evaluate the achievement and the degree of success of a given teaching method.

\subsubsection{Student's Learning Style}

Is the learner comfortable with the standard teaching techniques (logical charts, worksheets, exercises etc.)? Does the learner work better with note taking, hand-outs and repeating exercises? Certainly, given the nonorganization of delivery of subjects to teachers, we will end up with a class of learners with different learning styles. Therefore, if you have a class of mixed learning styles then you need to try to provide instruction using as many different methods as possible. Once you have answered these questions, you can more expertly approach the question of how you are going to provide the class with the grammar they need. In other words, each class is going to have different grammar needs and goals and it is up to the teacher to determine these goals and provide the means with which to meet them.

\subsection{The Objective}

\subsubsection{A Pre-Course Needs Analysis}

The key to beginning a successful grammar course is to clearly establish the students' interests and motivations. As part of a preliminary grammar course, the teacher is expected to get the students talk about what they like with an emphasis on usage of grammar in their studies, careers, jobs, and communication. The list resulting from the needs analysis may have prerequisites. We therefore need to decide with the students what their objectives for the coming course will be, for example: to develop their ability to discuss certain topics with more confidence, fluency, accuracy and awareness of relevant language.

With regard to these prerequisites, the research carried out aimed to make students' feedback for some foregrounded questions the basic starting point. The issue that university students try to manifest in their studying the course of grammar has usually been their desperate need to satisfy their academic needs.

Through a random selection, 36 university students from the English department (semester4) were handed a questionnaire as a pre-test needs analysis. The students were asked to respond according to their general needs while studying grammar.

\subsubsection{Needs Analysis (Survey Questionnaire)}

Please order the following suggestions according to your 
needs for grammar:

You would like to use Grammar for the sake of:

- Accuracy and Fluency: $36 \%$

- Academic Achievement: $30 \%$

- The improvement of various language skills: $25 \%$

- The understanding of the British and American culture: $10 \%$

\subsubsection{Set Short Term Objectives}

Given the data based feedback of our university students, Grammar is positively taken to be a source of a structured background for the overall academic achievement and communication. Therefore, the need for such grammar should be comprehensible in terms of topics and current affairs that tend to lend themselves to a great deal of discussion. It is important that the students don't feel that grammar or language input has been abandoned altogether. Although they may not want to follow a structural syllabus per se, there will be structural errors which repeatedly occur both in needs analysis and during the course and these will form the underlying framework for language input.

\section{The Research}

\subsection{The Problem}

Out of a small-scale research done recently, I found out that students' academic needs are not satisfied. First, student's language is in its average and most of the students' choice in studying grammar is because of good reasons like communication and better understanding of other subjects. Students' feedback has shown that $85 \%$ of the class has problems with verb tenses, the identification of mistakes and the breaking down the sentence into phrases and clauses. This output proves that students have problems with the usual basic grammar (Probably because

the teacher has to find out what stage of development the learners have reached before teaching a given item). Finally and most importantly, $82 \%$ of the class didn't know how to write a good paragraph while responding to the questions. The structural organization of ideas and the coherence of their paragraphs were terrible.In this respect, I can say that all my expectations about my students' level were to the point. The majority of the class has problems in the grammar and almost all students have serious problems in writing effective, organized and well-structured paragraphs. In addition to writing problems, students also have difficulty with academic reading. In short, they have difficulty seeing beneath the surface of the words to the complexity of the ideas expressed in complex language structures. In this respect, Mulroy (2003) forwards some excellent arguments for the teaching of grammar to anyone who uses language.

Sentences always have and always will consist of clauses with subjects and predicatesand words that fall into classes fairly well described as verbs, nouns, adjectives,adverbs, pronouns, prepositions, conjunctions, and interjections. Individuals who understand these concepts have a distinct advantage over others where the use of language is involved - and that mean everywhere. (p. 118)

To show how the proposed method of integrative grammar teaching can function and what students' attitude towards it will be, several lectures were conducted to seehow the method really works and what its potential is. The subjects were some 68 Moroccan students who have previously experienced studying grammar in secondary school and the university. The primary stage of the research has shown that mistakes are an integral part of their learning and that students have acquired some background knowledge but it is not systematized as shown in table (1):

Table 1: Students'grammatical problems:

\begin{tabular}{ll}
\hline Grammar 2 (Tense, Modal Verbs) & Grammmar 3 (sentences, phrases and clauses) \\
\hline 1. Tense shift & 1. Wrong identification of fragments \\
2. Wrong tense or verb form & 2. Comma Splice \\
3. Avoidance of mixed conditional types & 3. Run on, fused sentence \\
4. Misuse of non-restrictive relative clauses & 4. Dangling, misplaced modifier \\
5. Misuse of modals verb forms & 5. Unawareness of noun clauses \\
\hline
\end{tabular}

\subsection{The Procedure}

The analysis in this paper aims to foreground the students' grammatical problems and objectives with their various academic needs. Thus, the striking issue would be to start with a diagnosis of actual problems students have and to look for the possible remedial process to overcome those difficulties.

\subsection{The objective}

* To move from form to structure-discourse match

* To connect grammar teaching to everyday interaction (real world)

* To engage students in meaning-focused tasks

* To target consciousness-raising than formal teaching

* To enable the student to interact positively with all educational inputs

* To promote usage of grammar rules in writings

* To set up a comprehensive assessment based on exploration, practice and induction.

* To allow students to work in terms of an EPI (Exploration Practice Integration) Model. 


\subsubsection{Teaching Grammar 2 in Situational Contexts}

The objective of this course called Grammar 2 is to familiarize students with the basic grammatical items of the English Grammar. The syllabus is designed in a way to satisfy students' academic needs to understand and use the different tenses and modal verbs in different contexts. The methodology adopted is based on drills based on a specific choice of short texts in business, literature, linguistics or daily activities. The organization of the course is based on students' cooperation in the on-going process within a sort of teacher learner show. The movement from one grammatical item to another is expected to be smooth and reference is made to a situation or event that students suggest in their examples. Accordingly, the combinations of the grammatical items to different situations are proposed as in table2:

Table 2. Contextualized Grammatical Items.

\begin{tabular}{|c|c|}
\hline Situation or Context & Grammatical items \\
\hline Write a narrative (about a past experience or historical event) & Past tense \\
\hline $\begin{array}{l}\text { Give directions to a tourist to reach a given place, or Report daily schedules of students (in the class, } \\
\text { exams/tests,lectures, etc.) }\end{array}$ & Present tense \\
\hline Express future career moves & Future tense \\
\hline Express hope regret about some experiencea medical review on a visit with a new doctor. & Conditional tenses \\
\hline $\begin{array}{l}\text { Explain rules and regulations to someone, i.e. rules for the faculty cafeteria; doctor's instructions to } \\
\text { a sick patient, or give advice to a relative about his choice for the future }\end{array}$ & $\begin{array}{l}\text { Modal verbs: Can Must Should would may } \\
\text { need }\end{array}$ \\
\hline $\begin{array}{l}\text { Extend an invitation over the telephone to someone to come to a meeting, conference, party, Or } \\
\text { expressing preferences ( a questionnaire) }\end{array}$ & Verb Would like...Object \\
\hline $\begin{array}{l}\text { R React Exhibit a neutral position as in the discovery of somethingwrong in your office: use active } \\
\text { voice while stating a fact on the phone (oral communication) and the passive voicewhile writing a } \\
\text { report, an e-mail or a memo. }\end{array}$ & C A Active and passive \\
\hline
\end{tabular}

\subsubsection{Teaching Grammar 3 in terms of Expansion, Rehabilitation and Transformation of Sentences}

The major goal of teaching grammar 3 is to allow students to recognize how language operates. Using phrases, clauses and sentences requires the implementation of some materials that makes the recognition of how language operates a simplistic task for students. The new model recommends some involvement and cooperation of the layers of the teaching learning enterprise "student-teacher". The teacher's role is descriptive and explanatory; while that of the learner is studying the structure of English and reacting grammatically to it. This reaction of students is summarized in terms of expansion, rehabilitation and transformation of sentences as in the following:
A. Sentence
Expansion:
From
simple
to

ComplexSentences

1 Take a basic sentence:We like to be connected.

2 Expand on it: We like to be connected on line.

3 Expand again with additional information: We like to be connected on line from time to time.

4 Combine two sentences: We like to be connected on line from time to time. Our use of internet should be careful. We like to be connected online from time to time, so our use of internet should be wise.

5 Extend more/We like to be connected online from time to time, so our use of internet should be wise otherwise it will be a waste of time

6 Make substitutions to elaborate or link ideas:We like to be connected but carefully otherwise it will be a waste of time

7 Add information and construct a short narrative around the sentences students have created:

B. Sentence Rehabilitation,Sentence Recombination is not a Question of Paraphrasing.

It is an Effective Activity for TeachingParts of the Sentence, Sentence Structure, Paragraph Structure,punctuation, transition and coherence. Students must also use critical thinking skills to use and organize ideas and concepts. Sentence recombination exercises are content based and can be easily constructed in advance by the teacher or as a group activity with the students.

There are many variations on the paragraph or composition that students can create in this exercise. However, the efficiency of the method would be to explore students' awareness of the basic types of sentences like: the simple sentence, the compound sentence, the complex sentence and the compound complex sentence. This categorization of sentences is based on the number of clauses and the type of conjunctions used: coordinate and correlative conjunctions for compound sentences, while subordinate conjunctions are used with complex and compound complex sentences.

C. Sentence Transformation

The following sentence which requires the student's integration to solve writing and meaning based problem. The student's objective stems from his need to improve his language and the style that marks his better understanding and expression of his idea:

Unclear sentence:

Presumably, some students need some effective methods of teaching grammar than being taught abstract rules_ taught in some ways that are boring and impeding their language use and academic achievement

vs.

Much clearer:

Presumably, some students need some effective methods of teaching grammar rather than being taught abstract 
rules_that are boring and impeding their language use and academic achievement

The plausible approach to this process of sentence transformation is based on the type of error correction and the student's responsibility to overcome the problem. Occasionally, learners may need some explanations for certain grammatical structures. In fact, the combination of different approaches will certainly satisfy different learning styles. We also urge the adoption of the competency-based approach which constitutes the main theoretical framework within which the teacher has to proceed when teaching grammar.Nunan states that:

The concept of competency-based education (CBE) has been brought in to ESL from the field of adult education where it is used to specify the skills needed by adults to function in today's society in areas such as communication, problem-solving and interpersonal relationship, and computation, In ESL a competency is a task-oriented goal written in terms of behavioral objectives... It is not what the students know about Language, but what they do with the language. (Nunan 1988: 34)

The objective underlying students' involvement in the make-up of sentences requires from the teacher to engage new methods of comprehension and usage of a structured English language, correlate conscious-raising to better usage, combine assessment with team spirit and encourage learners to practice auto-learning and self-assessment. Innovations in method of language teaching, however, often fail to reflect the complexity of change in language teaching in that they fail to give adequate attention to the context in which a language is being taught. In particular, teacher characteristics such as level of professional learning and level of language proficiency and cultural dimensions such as expected learning and teaching styles, learner and teacher roles, expected outcomes of language learning and patterns of classroom interaction may have practical and positive impact on the learning teaching enterprise.

\subsection{Results and Implications}

Given the various methods adopted, we would like to check some of the issues raised and try to find out a plausible framework of grammar teaching. For this reason, a questionnaire was handed out to students about different items that we consider basic for the ongoing research project. The students belong to the English department, university of El Jadida, Morocco. The results have shown that $74 \%$ have no problem in grammar while $24 \%$ admitted to have serious problems in their grammar learning. Concerning the teaching issue, more than $44 \%$ consider the teacher and the method used to teach grammar to be the source of the problem; while $27 \%$ think that grammar is a complex subject of study. $77 \%$ of students consider writing to be directly monitored by their grammar in comparison to $6.81 \%$ for literature and $9.10 \%$ for translation.

With respect to these results, we would like to inquire about which method would give us the required effects of grammar teaching. Is it a question of implicit or explicit grammar teaching or just a question of the materials and the context where grammar is taught? Shall we focus instruction and expect a surface corrective feedback from students? Should we re-examine the course book and redesign it in a way that might make grammar a flexible academic subject and a positive tool for learning? These are some of the questions and issues that are supposed to have been the main concern of theoreticians and practitioners as well and therefore need some answers.

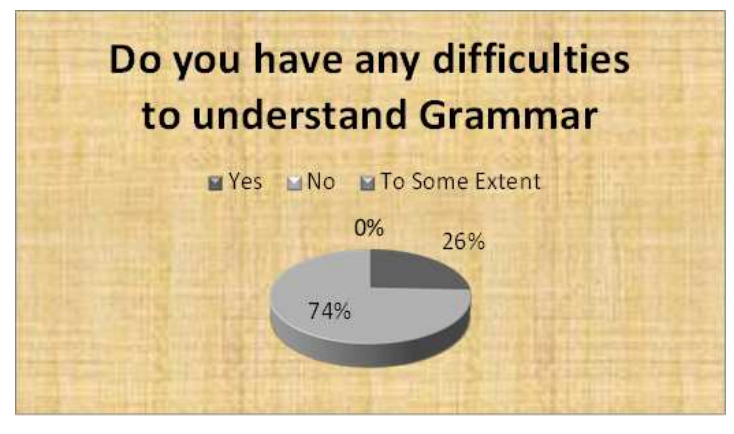

Figure 1. Students' grammar difficulties.

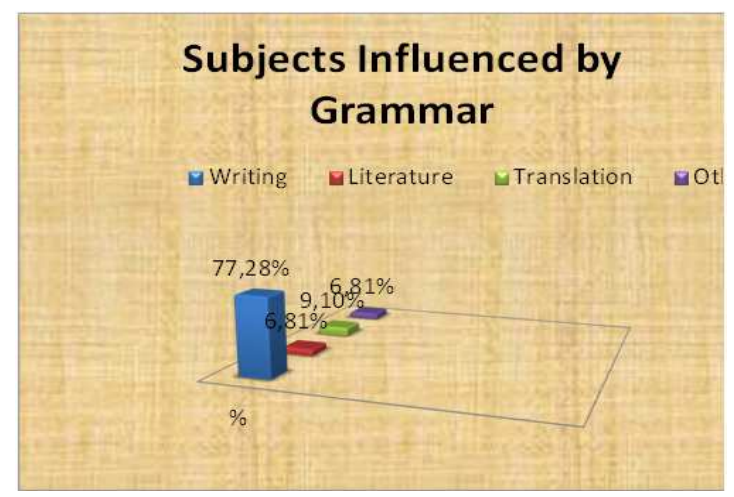

Figure 2. Academic influence of grammar.

Students' feedback shows that the need for grammar in their academic progress at the university relies on the link they find between grammar and other related subjects namely writing reading and translation. So the communicative issue is not a direct need but a peripheral issue that they don't deem important. However, the objective we need to achieve is to make our students able to monitor their competency-based skills. Fluency and accuracy, we believe, are two ingredients that make up a practical and more integrated learner of the language. Accordingly, the present paper aims to underline the difficulty and find out the plausible solution for a practical use of the language in different social and interpersonal interactions.

A major implication of the findings above is that students care about grammar as an academic subject and not as a powerful tool to implement their language use. Students are also expected to be the passive recipients of a rigid content where their involvement does not change anything in the teaching-learning enterprise. Being rule based, grammar is given a status to be a restricted domain of work or analysis 
and requires specific drills to fulfil the accuracy requirement of language.

With respect to the theoretical framework, grammar teaching is not a unique task but a combination of different tasks, materials, methods and assessment procedures. The variety of views advanced under the explicit teaching method agrees on the efficiency of the contextualized grammar teaching. The movement from students' apprehension from experience before comprehending from analysis is an interesting issue in that it allows a meaningful structural input for students. Also, the contextualized exposure to language within a principled communicative approach is a helpful issue for the present proposal. However, the present paper has shown the credibility of integration not only as a method but as a process where the integration of the materials, the resources and even assessment are involved.

Starting with the needs analysis, we could come over the intricate issue that may combine the teacher's method with the learner's academic and communicative needs. Exploration is the background to the student within a practical communicative atmosphere of learning will hopefully integrate the student, the teacher and the method, all as one. Accordingly, a movement from form to structurediscourse match where grammar teaching is linked to real world context will ensure students' engagement in meaningfocused tasks. Additionally, the findings have shown that targeting consciousness-raising will have the instant effect expected. As for assessment, the new model (EPI) allows the student to be aware of his mistakes and therefore his feedback towards errors will be integrative and communicative, given that he will be in charge of correction as well.

To make the above findings more useful for our readers and students, we will try to provide a proposal for grammar teaching and some remedies for an overall better performance in the teaching and learning of a foregrounding academic subject like grammar.

\section{Proposal and Remedial Work}

\subsection{The Present Survey}

The present paper is based on a small-scale attempt to find the answer. Because of time constraints, I have regrettably not been able to check all original sources, so my conclusions must be treated with caution; but I think the overall conclusions are sufficiently robust and merit serious consideration:

\subsection{The Teaching Situation}

The program designed for our students at Chouaib Doukkali University is actually not a proficiency course designed for university leavers who wish to enrol in any kind of teacher training. Instead, the syllabus designed for grammar $2 / 3$ targets the promotion of the four language skills especially writing. In the writing class, a series of poems were used to review and reinforce grammar rules the students should have 'learnt' while in school. This was deemed necessary as most of the students have limited to average English proficiency.

\subsection{The Proposal: An Integrative Model (EPI)}

\subsubsection{Methodology}

The proposed model (EPI) is based on an Exploration, Practice and Integration. These items fall into the teaching of grammar 2 and 3 at the university level. This proposal does not disregard the teaching of grammar rules and forms of language with regard to their foregrounding role in enhancing the basic structural input. However, this model provides a more comprehensible and efficient method based on exploration of the input, practice of the rules and integration of all interactive and comprehensible tools for the teaching of grammar and language. This model might become more interactive according to the following teaching-learning activities:

1 Start stating the academic and communicative objectives of the lesson.

2 Explore Students' awareness of the basic items like the sentence, phrase, clause, fragment, appositive, compound, complex, modifier etc. that will be needed to introduce, explain, or practice the new item. Many methodologists recommend that practice work be preceded by a presentation stage to ensure that the learners have a clear idea about what the targeted structure consists of.

3 Motivate the teaching of structures by showing how they are needed in real-life communication. Noticing forms of grammatical structures is a prerequisite for students' awareness of the language system.

4 Engage the students in varied guided comparisons or selection of grammatical structures and ask them to identify the new concept or the problem. (Note that it is assumed by Ellis that whereas practice is primarily behavioural, consciousness-raising is essentially concept forming in orientation).

5 Write two of the students' proposed structures on the board. Underline the new structure and use diagrams to involve them in the illustration of the relationship of the structure to other words and/or parts of the sentence.

6 Have the students use the structure with communicative expressions and familiar or new topics. Provide opportunities for more group work and peer interaction then a practical follow-up activity.

\subsubsection{The proposed Grammar Activities}

The common teaching strategies that tend to develop grammar activities tend to develop the kind of automatic control of grammatical structures that will enable learners to use them productively and spontaneously. It is common to distinguish a number of different types of practice activities -mechanical practice, contextualisedpractice, and 
communicative practice. Exploratory practice consists of various types of controlled activities where students are provided with sufficient data to work on as a background to explore the rules of the item to be taught. Contextualised practice is still controlled, but involves an attempt to encourage learners to relate form to meaning by showing how structures are used in real-life situations. Communicative practice entails various kinds of 'gap' activities which require the learners to engage in authentic communication while at the same time keeping an eye on the structures that are being manipulated in the process. The proposed grammar activities might be summarized as follows:

1 Explore student's background knowledge of the grammar item to be covered, including form, meaning, and use, and then describe them through a handful of examples. ( grammatical input)

2 Provide oral or written input ( eg, reading selection) that addresses the topic and review the point of grammar, using examples from the material (comprehensible input)

3 Have students to practice the grammar point in communicative drills that focus on the topic (grammatical output)

4 Have students do a communicative task on the topic (communicative output)

\subsubsection{Needs Analysis Objectives and Curriculum Design}

With respect to the integrative model and the grammar activities proposed, the student is supposed to be the focal participant to benefit from the teaching process. However, students are different in each class and so are their learning styles and needs. For this reason, identifying the linguistic, communicative and discourse features of the curriculum that need to be taught to a particular group of students indexes the starting point for the integrative grammar syllabus. An objective expectation of students' progress should take, while designing the syllabus, the following suggestions into consideration.

- A flexible lesson plan should be designed in a way to be changed once a given communicative or academic need arises.

- A flexible error correction should be performed to motivate the learner to ask for more exemplification and more meaningful practice.

- A practical and purposeful assessment should involve different types of practice to foster the objective needs and the real pitfalls of students' overall performance.

- The learning of different academic skills should link grammar needs to writing, reading comprehension and communication skills.

- Students integration in more conversational classroom activities will obviously help the student's grammatical and communicative competence to come up and be ready for acting.

Objectively, when a teacher develops a course curriculum, it is very helpful to connect students and make them participants and moderators of the whole design. The student will accordingly understand the method, the process and the objectives of the course. The grounding of these incremental factors in students' grammar course is probably a prerequisite to attain the objectives of the proposed Exploration, Practice and Integration model.

\section{Conclusion}

The teaching of grammar is by far, the most challenging task any Moroccan teacher may face in his/her daily classroom. Many do not wish to teach grammar explicitly, but they are keenly aware that students need an understanding of the rules to achieve fluency as well as accuracy. The formal syllabus in place in Moroccan universities is improvised by teachers of grammar focusing on form and disregarding the gist of meaning through communicative activities. Unfortunately, many students do not have adequate English proficiency to excel in their studies. One possible solution is thus, the blended or integrated approach to grammar teaching where there is a focus on the form but the activity is meaning and context based. The module of language and grammar study should be correlated with the improvement of students' writings, reading, communication and involvement in different academic tasks. It is to be noted that grammar is a foregrounding subject that targets the promotion of the different types of language input. The needs analysis has shown that students are aware of their academic and interactive needs. These needs should in a way be taken into consideration by teachers to set the appropriate goals. Given students' enthusiasm to learn the English language and about it, I suggest that grammar teachers should make reference to writing and linguistics as they are the closest subjects to grammar. Fragments or run-on sentences are however still persistent in students' writings, the fact which incorporates the role of the teacher and the learner in one enterprise called "Integration". The mistakes made may suggest a lack of concern for accuracy, perhaps an indirect effect of the communicative approach. In any case, the students found grammar class more challenging and interesting as evident from their feedback and that is in itself a major success to breaking the traditional view of grammar classes as dull and immensely structured.

\section{References}

[1] Beretta, A., \& Davies, A.(1985). Evaluation of the Bangalore Project. ELT Journal, 39 (2): 121- 127.

[2] Brown, H.D. (1994). Principles of Language Learning and Teaching, $3^{\text {rd }}$ ed. Englewood Cliffs, NJ : Prentice Hall.

[3] Celce-Murcia, NM., Dirnyei, Z., \&Thurell, S. (1997). Direct Approaches in L2 Instruction: A Turning Point in Communicative Language Teaching, TESOL Quarterly, 31: 141-152. 
[4] Craik, F.I.M., \& Lockhart, R.S. (1972). Levels of processing: A framework for memory research. Journal of Verbal Learning and Verbal Behavior, 11, 671-684.

[5] Cunico, S.(2005). Teaching language and cultural competence through drama: some suggestions for a neglected resource. Language Learning Journal, 31, 21-29.

[6] Ellis, R. (1994). The Study of Second Language Acquisition.Oxford : OUP.

[7] Holmes, V., \& Moulton, M.R. (2001).Writing Simple Poems. Oxford: OUP.

[8] Howatt, A.P.R. (1984). A History of English Language Teaching.Oxford : OUP.

[9] Islam, C. (2001). A different beginner textbook. Folio, 6(2), $15-19$.

[10] Kolb, D. (1984). Experiential learning: experience as the source of learning and development. Englewood Cliffs, NJ: Prentice Hall.

[11] Krashen, S. (1989). We acquire vocabulary and spelling by reading: Additional evidence for the input theory. Modern Language Journal, 73, 445-464.

[12] Krashen, S. (2004). The power of reading: insights from the research. Oxford: Heinemann.

[13] Maley, A. (2003).Creative approaches to writing materials. In B. Tomlinson (Ed.), Developing materials for language teaching (pp. 183-198). Cambridge: Cambridge University Press.

[14] Masuhara, H. (2000). Is reading difficulty a language problem? Implications of neuro-scientific research findings for reading pedagogy and materials development. The Language Teacher, 24(2).
[15] Masuhara, H. (2003). Materials for developing reading skills In B. Tomlinson (Ed.), Developing materials for language teaching (pp. 340-363). Cambridge: Cambridge University Press.

[16] Mukundan, J. (Ed.) (2005a). Readings on ELT Materials II. Petaling Jaya: Pearson Malaysia.

[17] Mulroy, D. (2003). The war against grammar. Portsmouth, NH: Boynton/Cook Publishers, Inc.

[18] Musumeci, D. (1997). Breaking the Tradition: An Exploration of the Historical Relationship between Theory and Practice in Second Language Teaching. NY: McGraw Hill.

[19] Nunan, D. 1988: Syllabus design. Oxford: Oxford University Press.

[20] Renandya, W.A., (Ed.) (2005). Methodology and materials design in language teaching: current perceptions and practices and their implications. Singapore: RELC.

[21] Spada, N., \& Lightbown (1993). Instruction and the Development of Questions in the L2 Classroom.

[22] Studies in Second Language Acquisition, 15: 205-224.

[23] Stern, H.(1984). Fundamental Principles of Language Teaching.Oxford : OUP.

[24] Sysoyev, P.V. (2003). Integrative L2 Grammar Teaching: Exploration, Explanation and Expression.

[25] Ur, P. (1988). Grammar Practice Activities. Cambridge, CUP

[26] http://iteslj.org/Articles/Sysiyev integrative.html.

[27] http://www.umb.edu/academic programs/departments/apling/facstaff/documents/EllisGrammarTeachingPracticeorConsciousnessRaising.doc 